\title{
Patients Opinion on the use of Generics and Factors Associated with it: A Cross-sectional Study
}

\author{
Jaykaran Charan ${ }^{1, *}$, Mayur Chaudhari ${ }^{2}$, Deepak Saxena ${ }^{3}$, Pankaj Bhardwaj ${ }^{4}$, Pradeep Dwivedi ${ }^{1}$, Sneha Ambwani ${ }^{1}$ \\ 'Department of Pharmacology, All India Institute of Medical Sciences, Jodhpur, Rajasthan, INDIA. \\ 2Department of Pharmacology, Government Medical College, Surat, Gujarat, INDIA. \\ ${ }^{3}$ Department of Epidemiology, Gandhinagar, Gujarat, INDIA. \\ ${ }^{4}$ Department of Community and Family Medicine, All India Institute of Medical Sciences, Jodhpur, Rajasthan, INDIA.
}

\begin{abstract}
Background: Generic drugs (Generics) are low cost, equal efficacy alternatives to the branded drugs. Generics are medicines on which patents have expired. They are sold either as branded products or as unbranded products under generic names. These generic names are internationally agreed short names called International Non-Proprietary Names. Due to its low cost, it reduces the overall expenditure for patient care. Government of India (GOI) has been pushing to increase the prescription practice of doctors for generics and acceptability of generic in the community. Present study assesses the current opinion of patients about the generics and documents factors affecting the knowledge, perception and opinion about the generics. Objectives: Present study was designed to investigate about the opinion of patients about the generics and to document different factors associated with their perceptions. Materials and Methods: A pre-validated pre-tested questionnaire was used to collect the data from patients attending various outpatients in a Tertiary Care hospital in Jodhpur. Trained Research Associate visited various Out Patient Department (OPD) of different specialties for two consecutive days to seek consent and collected data from the patients visiting the OPD and consented to participate. Patient's knowledge, prior experience of use and general opinion about the generics was gathered. Descriptive statistics was used in the form of frequency and percentages. Results: Out of the 643 patients, $147(22.9 \%)$ had heard about the generics. Out of the different sociodemographic predictors, age with a class intervals 45 years- 55 years $(O R-2.52), 55$ years -65 years $(O R-3.26)$ and $>65$ years $(O R-3.09)$
\end{abstract}

and educational qualifications namely higher secondary (OR - 3.07) and graduation (OR - 5.98) were found to be the statistically significant predictors for the opinion on generics; however, gender, marital status, family income and occupation were not significant statistically. Out of the 147 patients who had heard about the generics only $38 \%$ had used them in last six months, $65.8 \%$ agreed that generics are safe and $36.7 \%$ opined that generics are as effective as branded drugs. Around $44 \%$ of the patients disagreed that generics have more side effects. On inquiring about the most common reason for no usage of the generic drug, distrust on the efficacy was found to be the most common one. Conclusion: Majority of patients had never heard about the generic drugs. Age and Education were the positive predictors for better awareness about the generic drugs. Patients perception for generics can be changed with better advocacy as well as informed prescription by the treating physicians.

Key words: Generic Drugs, Brand Drugs, Opinion, Patients, Physicians, India.

\section{Correspondence}

Dr. Jaykaran Charan, Assistant Professor, Department of Pharmacology, All India Institute of Medical Sciences, Jodhpur, Rajasthan, INDIA.

Phone: +91-9825219196

Email: dr.jaykaran78@gmail.com

DOI: 10.5530/jyp.2019.11.36

\section{INTRODUCTION}

As per United States Food and Drug Administration (FDA), a generic drug is intended to work same as approved branded drug in dosage form, safety, route of administration, quality and performance. It contains same active ingredient as branded counterpart. ${ }^{1}$ Generic drug (Generics) is expected to provide same benefits as branded drugs with low cost but with same quality. World Health Organization (WHO) labeled generics as Multisource pharmaceutical product which is pharmaceutically equivalent to innovator product. ${ }^{2}$ It is hypothesized that with the increase in acceptance of generics by all the stakeholders, costs of medical care will decrease and hence many countries took initiative to promote use of generics in patient care and India is one of them.

Government of India launched an innovative scheme Pradhan Mantri Bhartiya Janaushadhi Pariyojana (PMBJP) in 2016. Under this scheme, Pradhan Mantri Bhartiya Jan Aushadhi Kendra (PMBJK) were opened in 850 centers, across 28 states to provide generics at affordable cost Jan Aushadhi stores are operated by Bureau of Pharma Sector Undertakings (BPSU) of India, Department of Pharmaceuticals. Generics through these stores can be purchased at cheaper rates due to the lower tax rate levied on these medicines. ${ }^{3}$ Success of PMBJP depends on intensity of efforts to change the opinion and perception about the generics drugs amongst stakeholders including patients, doctors and pharmacists.

Indian Medical Council regulations 2002 passed an amendment in 2016 to direct all the physicians registered under MCI to prescribe generic drugs ${ }^{4}$ However, one of the important stake holders for generics is the consumer himself. It's consumer demand on prescription of generics from the treating physician and/or request for switching brand with generic to pharmacist will be key to success of PMBJP. Acceptability of generics by the patients depends on various factors like their perceptions, opinion and factors that may affect their perception regarding generics drugs. There has been anecdotal evidence regarding misconceptions and trust issues for the generic medicines as reported by the patients. Majority of evidence for perception of generic medicine are available from western countries where generic substitution is a common practice, however, there are very few studies documenting opinion of Indian patients about generics. ${ }^{5}$ Majority of these studies have a smaller sample size along with other limitation of serious methodological issues. Hence there was an urgent need for a robust study to know the patient's perception toward the generics and to explore various factors which may

This is an open access article distributed under the terms of the Creative Commons Attribution-NonCommercial-ShareAlike 4.0 License, which allows others to remix, tweak, and build upon the work non-commercially, as long as the author is credited and the new creations are licensed under the identical terms. 
affect patient's awareness about the same. Such insights will be valuable in designing information and educational interventions.

\section{MATERIALS AND METHODS}

\section{Study sample}

Present study was conducted at an institute of National Importance and tertiary level care health facility in Jodhpur - Rajasthan. Permission from the Institution Ethics Committee was obtained before initiating the study (AIIMS/IEC/2017/279). The study was conducted between February and March 2017. Samples of 643 patients were chosen from the patients attending different OPDs. Patients with more than 18 years of age and visiting OPDs of AIIMS Jodhpur were included in the study after obtaining informed consent. Patients from any department except from Psychiatry and Physiotherapy OPD were included in the study. The sample size was calculated by the Open Epi software Version 3.01. The estimated sample size was based on the pilot study conducted at same tertiary care institution before initiation the study. In the pilot study, the awareness about the generics was observed in $41 \%$ of the patients, hence at a proportion of patients with the correct knowledge on generics as $41 \%, 5 \%$ permissible error and $99 \%$ confidence interval, the sample size was found to be 642 patients.

The non-response rate for participation in present study was $6.8 \%$. There was no significant difference between age, gender and locality (Rural/ Urban) between those who participated in the study and who had not consented to participate in study.

\section{Survey Instrument development and data collection}

The survey instrument was prepared in vernacular language by undertaking a descriptive review of the previous published studies in the domain of generics. The draft instrument was further discussed amongst the investigators and was sent to experts for validation based on face, content and constructs validity. The tools were pre-tested and the initial draft was revised based on observations of pre-testing before actual execution to the patients.

The data collection was done by a data collector, trained for conducting the patient interview based on the survey instrument. Only those who consented to be a part of study were included. The questions were asked from the proforma both in Hindi as well as Rajasthani language. The data collector visited each of OPD for two days. The schedule for visit to OPD was fixed randomly by using simple randomization through computer generated numbers. All patients who visit on the day of data collection were offered to participate. Survey instrument was having both closed as well as open ended questions.

\section{Statistical analysis}

Statistical Analysis Frequency and percentages were used for descriptive analysis. Logistic regression was used to assess the sociodemographic factors which may affect patient's awareness about the generic drugs. SPSS Statistics for Windows, Version 17.0. Chicago: SPSS Inc. was used for analysis.

\section{RESULTS}

Information from a total of 643 patients was gathered from the different OPDs of the institution. Out of these 643 patients, majority were below 65 years of age. Median age of the patients was 37 years. Around $62 \%$ were males and around $48 \%$ were residing in urban locality. Almost onethird of the patient had educational qualification of graduation level or above. Monthly family income of almost $70 \%$ of patients was less than 40000 INR per months and around $7 \%$ of the patients were employed in government jobs while majority of the females were house wives. [Table 1]
Out of 643 patients, 147 (22.9\%) had heard about the generics previously and had some understanding about it. Age with a class intervals 45 years - 55 years $(\mathrm{OR}-2.52), 55$ years - 65 years $(\mathrm{OR}-3.26)$ and $>65$ years (OR -3.09) and educational qualifications namely higher secondary $(\mathrm{OR}-3.07)$ and graduation $(\mathrm{OR}-5.98)$ were found to be the significantly associated with the awareness about generic drugs. Amongst the educational qualifications higher secondary (OR - 3.07) and graduation (OR - 5.98) were significantly associated with the awareness about the generic drugs. There was no significant association found between

Table 1: Sociodemographic characteristics of patients included in the study.

\begin{tabular}{|c|c|}
\hline Sociodemographic Parameters & Frequency (Percentages) \\
\hline \multicolumn{2}{|l|}{ Age Group (Years) } \\
\hline$\leq 25$ & $183(28.5)$ \\
\hline $25-35$ & $120(18.7)$ \\
\hline $35-45$ & $125(19.4)$ \\
\hline $45-55$ & $101(15.7)$ \\
\hline $55-65$ & $73(11.4)$ \\
\hline$>65$ & $41(6.4)$ \\
\hline \multicolumn{2}{|l|}{ Gender } \\
\hline Male & $399(62.1)$ \\
\hline Female & $244(37.9)$ \\
\hline \multicolumn{2}{|l|}{ Locality } \\
\hline Urban & $309(48.1)$ \\
\hline Rural & $334(51.9)$ \\
\hline \multicolumn{2}{|l|}{ Marital Status } \\
\hline Married & $504(78.4)$ \\
\hline Unmarried & $139(21.6)$ \\
\hline \multicolumn{2}{|l|}{ Education Qualification } \\
\hline No formal education & $157(24.4)$ \\
\hline Primary & $98(15.2)$ \\
\hline Secondary & $98(15.2)$ \\
\hline Higher Secondary & $92(14.3)$ \\
\hline Graduation & $198(30.8)$ \\
\hline \multicolumn{2}{|l|}{ Family Income (INR)/Month } \\
\hline$\leq 20000$ & $434(67.5)$ \\
\hline $20000-40000$ & $131(20.4)$ \\
\hline $40000-60000$ & $53(8.2)$ \\
\hline $60000-80000$ & $8(1.2)$ \\
\hline$>80000$ & $17(2.6)$ \\
\hline \multicolumn{2}{|l|}{ Occupation } \\
\hline Daily Labourer & $47(7.3)$ \\
\hline Self-employed & $75(11.7)$ \\
\hline Government Job & $47(7.3)$ \\
\hline Private Job & $70(10.9)$ \\
\hline House-Wife & $191(29.7)$ \\
\hline Not Working & $41(6.4)$ \\
\hline Student & $116(18)$ \\
\hline Others & $56(8.7)$ \\
\hline
\end{tabular}

Values in parenthesis are percentages. 
Table 2: Factors affecting knowledge of generics drugs in patients included in the study.

\begin{tabular}{|c|c|c|c|}
\hline Variables & OR & $95 \% \mathrm{Cl}$ of OR & $P$ Value \\
\hline \multicolumn{4}{|l|}{ Age Group (Years) } \\
\hline$\leq 25$ & 1.00 & & \\
\hline $25-35$ & 0.91 & $0.42-1.93$ & 0.797 \\
\hline $35-45$ & 1.50 & $0.64-3.50$ & 0.350 \\
\hline $45-55$ & 2.52 & $1.04-6.08$ & 0.040 \\
\hline $55-65$ & 3.26 & $1.28-8.27$ & 0.013 \\
\hline$>65$ & 3.09 & $1.02-9.31$ & 0.045 \\
\hline \multicolumn{4}{|l|}{ Gender } \\
\hline Male & 1.00 & & \\
\hline Female & 0.83 & $0.41-1.68$ & 0.607 \\
\hline \multicolumn{4}{|l|}{ Locality } \\
\hline Urban & 1.00 & & \\
\hline Rural & 1.12 & $0.72-1.73$ & 0.619 \\
\hline \multicolumn{4}{|l|}{ Marital Status } \\
\hline Married & 1.00 & & \\
\hline Unmarried & 1.01 & $0.41-2.52$ & 0.972 \\
\hline \multicolumn{4}{|l|}{ Education Qualification } \\
\hline No formal education & 1.00 & & \\
\hline Primary & 0.83 & $0.33-2.07$ & 0.682 \\
\hline Secondary & 2.00 & $0.86-4.71$ & 0.109 \\
\hline Higher Secondary & 3.07 & $1.32-7.13$ & 0.009 \\
\hline Graduation & 5.98 & $2.76-12.97$ & 0.000 \\
\hline \multicolumn{4}{|c|}{ Family Income (INR)/Month } \\
\hline$\leq 20000$ & 1.00 & & \\
\hline $20000-40000$ & 1.56 & $0.94-2.61$ & 0.087 \\
\hline $40000-60000$ & 1.39 & $0.69-2.78$ & 0.354 \\
\hline $60000-80000$ & 1.79 & $0.38-8.44$ & 0.462 \\
\hline$>80000$ & 2.12 & $0.72-6.26$ & 0.174 \\
\hline \multicolumn{4}{|l|}{ Occupation } \\
\hline Daily Labourer & 1.0 & & \\
\hline Self-employed & 1.67 & $0.42-6.60$ & 0.464 \\
\hline Government Job & 3.56 & $0.87-14.52$ & 0.077 \\
\hline Private Job & 3.26 & $0.85-12.50$ & 0.084 \\
\hline House-Wife & 3.07 & $0.72-13.14$ & 0.130 \\
\hline Not Working & 1.42 & $0.32-6.40$ & 0.644 \\
\hline Student & 2.84 & $0.66-12.20$ & 0.162 \\
\hline Others & 1.22 & $0.27-5.39$ & 0.797 \\
\hline
\end{tabular}

gender, marital status, family income and occupation with the awareness of generic drugs. [Table 2]

Out of the 147 patients who had heard about the generic drugs, 38\% had used them in last six months. $66 \%$ patients either agree or strongly agree for the statement that generics are safe while around 37\% agree or strongly agree for the statement that generics are as effective as brands. Around $43 \%$ patients disagree with the view that generic drug causes more side effects than brand name drugs. Majority of the patients strongly felt that generics are cheaper than brand name drugs. Around half of

\section{Table 3: Perception of patients regarding generics.}

Have you ever heard about generic drugs? $(n=643)$

Yes

$147(22.9)$

No

$495(77.1)$

Have you used generics in the last 6 months? $(n=147)$

$\begin{array}{ll}\text { Yes } & 56(38 \%) \\ \text { No } & 91(62 \%)\end{array}$

Generics are safe $(n=114)$

Strongly Agree

$23(20.2)$

$52(45.6)$

$20(17.5)$

$13(11.4)$

$6(5.3)$

Generics are as effective as branded drugs $(n=109)$

$\begin{array}{cc}\text { Strongly Agree } & 12(11) \\ \text { Agree } & 28(25.7) \\ \text { Neutral } & 44(40.3) \\ \text { Disagree } & 21(19.3) \\ \text { Strongly Disagree } & 4(3.7)\end{array}$

Can cause more side effects than brand drug $(n=103)$

$\begin{array}{cc}\text { Strongly Agree } & 7(6.8) \\ \text { Agree } & 17(16.5) \\ \text { Neutral } & 34(33) \\ \text { Disagree } & 42(40.8) \\ \text { Strongly Disagree } & 3(2.9)\end{array}$

$88(75.2)$

$11(9.4)$

$11(9.4)$

$4(3.4)$

$3(2.6)$

Do you trust Generic Drug are effective? $(n=147)$

Yes

$79(53.7)$

$68(46.3)$

Are you willing to use generics now a days? $(n=147)$

Yes

$73(49.7)$

$74(50.3)$

If no, which are the reasons preventing you from using generics $(n=66)$

I do not know about them

$18(27.3)$

$2(3)$

My physician does not know about them

0

My pharmacist does not know about them

$39(59.1)$

I do not trust them

$1(1.6)$

I had a bad experience in the past

I cannot find them easily at my pharmacy

Has ever a physician or a pharmacist proposed/ recommended you substitute a branded drug with a generic drugs? $(n=135)$

Yes

Continued.. 
Table 3: Cont'd.

$$
\text { No }
$$

$16(11.9)$

I don't know

If yes, have you followed that proposition/ recommendation? $(n=119)$

Yes

$117(98.3)$

No

$2(0.7)$

Have you used a generic drug, after having used the relevant branded? $(n=79)$

Yes

No
If yes, were you satisfied with the generic drug? $(n=17)$

Yes

$16(94.1)$

No

$1(5.9)$

I don't know

Please indicate the level of agreement with the following statements

I would substitute a branded drug with a generic because $(n=75)$

My doctor recommend it

74 (98.6)

My pharmacist recommend it

0

Friends/relatives recommend it

0

The generics is cheaper

$1(1.4)$

Values in parenthesis are percentages.

the patients supported the efficiency of generics and were willing to use generics in future. Most common reason for not using generic drugs was not trusting the efficiency of these drugs. [Table 3]

\section{DISCUSSION}

This study was conducted to know the knowledge and perception of patients about the generic use. It was observed that overall awareness about the generics was inadequate. Age between 45-55 years and education above higher secondary were significant predictors for the awareness about generic drugs. Regarding the efficacy of generics, the opinion was shared, half of the patients considered the efficacy of generic drug as good as brand and were willing to use it in future while rest did not trust the efficacy of these drugs and did not want to use generics in future. Inadequate awareness about the generics was also observed in other published studies amongst non-Indian patients but overall awareness in present study was less as compared to other studies published for non-Indian patients. ${ }^{6-9}$ There is a paucity of quality studies published from India regarding the patients' perception about the generic drugs. In spite of various promotional activities undertaken by government regarding generics, a very poor awareness was documented in present study. Recently some aggressive steps are further taken by the government to promote use of generics in the day-to-day practice, but these steps are largely directed to the prescribers and but not to the consumers / patients. Better communication between patients and doctors is key for generating better awareness about the generic medicines. ${ }^{10}$ In this study almost $100 \%$ patients (out of those who knows about generic drugs) agreed to substitute the brand with generic if it is suggested by the physician. Similar results were also observed in some studies published for other countries. ${ }^{11}$ Physician can communicate information about efficacy and cost of generics to the patients and that may not only increase the awareness but also enhance the acceptability of generics and change in the perception towards its use. ${ }^{12,13}$ In a published study, poor communication with the physician was negative predictor for the use of generic drugs. ${ }^{14}$ Role of physician hence becomes very important for spreading the right information about the generics to patients and can only be possible if physicians themselves believe in the equal efficacy and less cost of generics as compared to brands. ${ }^{15,16}$ Physicians normally have an individual choices for prescribing drugs which is largely based on brand names. Change in focus from brands to generics will requires adequate efforts by the administrators, physicians' associations and government. It is also important to assess their belief about the generics as few studies suggest that many physicians are not aware about the bioequivalence criteria for the generics which equates the effect of generics with branded drugs..$^{17-19}$

In the present study out of $23 \%$ of patients those who had heard about the generics, only $38 \%$ had used the generics in last six months narrating a low use of generics. The main reason could be, conventionally, the choice of drug is decided by physicians and patients have a very limited role. This also might lead to poor awareness along with the misconceptions about the generic drugs. There are consistent findings in various studies which shows that even after having awareness about the generic drugs, patients don't wish to use it because of various misconceptions. ${ }^{19,20}$ In present study, out of all patients who had heard about generics only $53.7 \%$ trusted their efficiency, similar findings were observed in other studies published from many countries. ${ }^{15,20,21-24}$

In present study out of all the patients who had heard about generics, $75 \%$ strongly agreed that these drugs are cheaper as compared to brand. As per the previously published studies, patients associate less cost with the less quality and this may be the reason for not using the generics instead of knowing about it. ${ }^{15,20,23}$ This finding is interesting because the main rationale of use of generic drug is to reduce the cost while the same logic is used to consider the drug of inferior quality and this goes against the efforts to promote the generic drug in standard clinical practice. As per the published literature, all the factors which may increase the use of generics like lower income, poor health and high out of pocket expenditure are not found to be associated with use of generic drugs. This shows that right information has not yet reached to patients. More efforts are needed towards advocacy for the use of generic drugs.

Two factors which were found to be associated with the awareness of generics in this study were age above middle age and high education. Association between education and awareness of generic drug was also observed in previously conducted research..$^{22,24-26}$ Higher age is also found to be associated with awareness of generics in other studies. It is observed that people having more age are usually consuming more drugs and having more educational qualifications which may increase the chance of knowing more about the generic drugs. There was no association found between gender, family income and occupation with awareness of generic drugs. In few studies it was observed that females have more awareness about the generics as compared to males while in some other studies no such differences were found. ${ }^{27,28}$ In this study majority of the females were housewives and having less education so it might have negatively affected the awareness about the generic drugs.

This study was conducted at a government run tertiary care center. So, findings cannot be generalized to all Indian patients. Patients attending private health care facilities, may have different socioeconomic status in comparison to patients attending government facility, which may affect awareness understanding about generic drugs. As the aim of the study was to evaluate overall opinion about the generic drugs hence no comparison was done for the different categories of drugs and data related to disease conditions were not collected. Acute and Chronic disease conditions may affect the opinion of patients about the generic drugs hence such information if collected, may enhance the robustness 
of the study. To the best of our awareness, there is no published study with adequate sample size from the India wherein patients' opinion or perception is assessed about the generics and this is an honest attempt to get first glimpse of it. We observed that awareness and acceptability of generics is very inadequate and there is a need of proper dissemination of information as well as advocacy to patients. There is also a need to arrange proper training of physicians regarding various myths affecting the use of generics in Indian setting. Patient being a very important stakeholder has all rights to demand generic drug prescription form physicians but to reach that stage patient must have good awareness about basics of the generic drugs. Ideally it is expected from a physician to provide correct and adequate information about generics for making informed choice by patients but either the physicians are prejudiced or have no adequate time to inform patients or they themselves have misconceptions. Strong advocacy by doctors by sharing information with the patients about generic drug may not only increase the awareness but may change the perception and help the informed patients in the decision process. ${ }^{29-32}$

\section{CONCLUSION}

Awareness about the generics are very low in population included in this survey. Age and education of the participants were positively associated with the awareness about the generic drugs.

\section{ACKNOWLEDGMENT}

We want to acknowledge Indian Council of Medical Research for providing us the grant for conduction of this study. We also want to acknowledge research assistant and data entry operator involved in this project.

\section{CONFLICT OF INTEREST}

The authors declare no conflict of interest.

\section{ABBREVIATIONS}

FDA: Food and Drug Administration; WHO: World Health Organization; PMBJP: Pradhan Mantri Bhartiya Janaushadhi Pariyojana.

\section{Source of support}

Indian Council of Medical Research Extra mural project - IRIS -20121888.

\section{REFERENCES}

1. Administration USFaD. Generic Drug Facts. The Institution. 2017. [updated 10/06/2017 cited 2018 24/02]; Available from: https://www.fda.gov/Drugs/ ResourcesForYou/Consumers/BuyingUsingMedicineSafely/GenericDrugs/ ucm167991.htm.

2. Organization WH. WHO General Guidance on Variations to Multisource Pharmaceutical Products. The Institution, Geneva, Switzerland. 2015. [cited 2018 24/02]; Available from: http://www.who.int/medicines/areas/quality_safety/ quality_assurance/VariationsMultisourcePharmaceuticalProducts_QAS14-575_ Rev1clean02062015.pdf

3. Deshpande P, Sheriff M, Pawar A. Functioning and productivity of Jan Aushadhi stores in India: The owners perspective. CHRISMED Journal of Health and Research. 2018;5(1):28-37.

4. $\mathrm{MCl}$. Indian Medical Council (Professional Conduct, Etiquette and Ethics) Regulations, 2002. Medical Council of India, New Delhi. 2016. [cited 2018 24/02];Availablefrom:https://www.mciindia.org/documents/rulesAndRegulations/ Ethics\%20Regulations-2002.pdf.

5. Das M, Choudhury S, Maity S, Hazra A, Pradhan T, Pal A, et al. Generic versus branded medicines: An observational study among patients with chronic diseases attending a public hospital outpatient department. J Nat Sci Biol Med.
2017:8(1):26-31

6. Skaltsas LN, Vasileiou KZ. Patients' perceptions of genericsin Greece. Health Policy. 2015;119(11):1406-14.

7. Babar ZU, Stewart J, Reddy S, Alzaher W, Vareed P, Yacoub N, et al. An evaluation of consumers' knowledge, perceptions and attitudes regarding generic medicines in Auckland. Pharm World Sci. 2010;32(4):440-8.

8. Dunne S, Shannon B, Dunne C, Cullen W. Patient perceptions of generic medicines: a mixed-methods study. Patient. 2014;7(2):177-85.

9. Drozdowska A, Hermanowski T. Exploring the opinions and experiences of patients with generic substitution: a representative study of Polish society. Int J Clin Pharm. 2015;37(1):68-75.

10. Tarn DM, Heritage J, Paterniti DA, Hays RD, Kravitz RL, Wenger NS. Physician communication when prescribing new medications. Arch Intern Med. 2006;166(17):1855-62.

11. El-Dahiyat F, Kayyali R. Evaluating patients' perceptions regarding generic medicines in Jordan. J Pharm Policy Pract. 2013;6(1):3. doi:10.1186/2052-3211-6-3.

12. Alexander GC, Casalino LP, Meltzer DO. Patient-physician communication about out-of-pocket costs. JAMA. 2003;290(7):953-8.

13. Shrank WH, Joseph GJ, Choudhry NK, Young HN, Ettner SL, Glassman P, et al. Physicians' perceptions of relevant prescription drug costs: do costs to the individual patient or to the population matter most?. Am J Manag Care. 2006;12(9):545-51.

14. Iosifescu A, Halm EA, McGinn T, Siu AL, Federman AD. Beliefs about genericsamong elderly adults in hospital-based primary care practices. Patient Educ Couns. 2008:73(2):377-83.

15. Dunne SS. What Do Users of Generic Medicines Think of Them? A Systematic Review of Consumers' and Patients' Perceptions of and Experiences with, Generic Medicines. Patient. 2016;9(6):499-510.

16. Kobayashi E, Karigome H, Sakurada T, Satoh N, Ueda S. Patients' attitudes towards generic drug substitution in Japan. Health Policy. 2011;99(1):60-5.

17. Banahan $\mathrm{BF}$, Kolassa EM. A physician survey on genericsand substitution of critical dose medications. Arch Intern Med. 1997;157(18):2080-8

18. McGettigan P, McManus J, O'Shea B, Chan R, Feely J. Low rate of generic prescribing in the Republic of Ireland compared to England and Northern Ireland: prescribers' concerns. Ir Med J. 1997;90(4):146-7.

19. Wilner AN. Therapeutic equivalency of generic antiepileptic drugs: results of a survey. Epilepsy Behav. 2004;5(6):995-8

20. Keenum AJ, Devoe JE, Chisolm DJ, Wallace LS. Generic medications for you, but brand-name medications for me. Res Social Adm Pharm. 2012;8(6):574-8.

21. Shrank WH, Cadarette SM, Cox E, Fischer MA, Mehta J, Brookhart AM, et al. Is there a relationship between patient beliefs or communication about genericsand medication utilization?. Med Care. 2009;47(3):319-25.

22. Himmel W, Simmenroth-Nayda A, Niebling W, Ledig T, Jansen RD, Kochen MM, et al. What do primary care patients think about generic drugs?. Int J Clin Pharmacol Ther. 2005;43(10):472-9.

23. Kjoenniksen I, Lindbaek M, Granas AG. Patients' attitudes towards and experiences of generic drug substitution in Norway. Pharm World Sci. 2006;28(5):284-9.

24. Colgan S, Faasse K, Martin LR, Stephens MH, Grey A, Petrie KJ. Perceptions of generic medication in the general population, doctors and pharmacists: a systematic review. BMJ Open. 2015;5(12):e008915. doi: 10.1136/bmjopen-2015-008915.

25. Pereira JA, Holbrook AM, Dolovich L, Goldsmith C, Thabane L, Douketis JD, et al. Are brand-name and generic warfarin interchangeable? A survey of Ontario patients and physicians. Can J Clin Pharmacol. 2005;12(3):e229-39.

26. Valles JA, Barreiro M, Cereza G, Ferro JJ, Martinez MJ, Escriba JM, et al. A prospective multicenter study of the effect of patient education on acceptability of generic prescribing in general practice. Health Policy. 2003;65(3):269-75.

27. Wijk BLV, Klungel OH, Heerdink ER, DeBoer A. Generic substitution of antihypertensive drugs: does it affect adherence?. Ann Pharmacother. 2006;40(1):15-20.

28. ShrankWH, Cox ER, Fischer MA, Mehta J, Choudhry NK. Patients' perceptions of generic medications. Health Aff. 2009;28(2):546-56

29. Nardi EP, Ferraz MB, Pinheiro GR, Kowalski SC, Sato El. Perceptions of the population regarding genericsin Brazil: a nationwide survey. BMC Public Health. 2015;15(1):117.

30. Shrank WH, Hoang T, Ettner SL, Glassman PA, Nair K, DeLapp D, et al. The implications of choice: prescribing generic or preferred pharmaceuticals improves medication adherence for chronic conditions. Arch Intern Med. 2006;166(3):332-7.

31. Shrank WH, Fox SA, Kirk A, Ettner SL, Cantrell CH, Glassman P, et al. The effect of pharmacy benefit design on patient-physician communication about costs. J Gen Intern Med. 2006;21(4):334-9.

32. Bloor K, Freemantle N. Lessons from international experience in controlling pharmaceutical expenditure. II: Influencing doctors. BMJ. 1996;312(7044):1525-7. 